\title{
Analisis Dukungan Organisasional Persepsian dan Employee Engagement terhadap Kinerja Karyawan: Kepuasan Kerja sebagai Pemediasi
}

\author{
Yuni Siswanti ${ }^{1 *}$, Krisnandini Wahyu Pratiwi ${ }^{2)}$ \\ ${ }^{1 *, 2)}$ Prodi Manajemen, Fakultas Ekonomi dan Bisnis,Universitas Pembangunan Nasional \\ "Veteran" Yogyakarta \\ J1. SWK 104, Condong Catur, Depok, Sleman, Yogyakarta 55283 \\ E-mail: yuni.siswanti@upnyk.ac.id ${ }^{\left.1^{*}\right)}$
}

\begin{abstract}
This study aims to analyze the effect of perceived organizational support (POS) and employee engagement on performance and the role of job satisfaction in mediating the effect of perceived organizational support (POS) and employee engagement on performance. The population in this study were permanent employees at PT. Solusi Bangun Indonesia Tbk. The research method used was a survey and a sample size of 185 employees. The research instrument adopted from previous research. Retrieval of data by means of questionnaires and interviews. Validity and reliability tests show all questionnaire items are valid and reliable. To test $\mathrm{H} 1$ and $\mathrm{H} 2$ with simple regression, $\mathrm{H} 3$ and $\mathrm{H} 4$ test with Baron and Kenny regression model. The results of hypothesis testing show that: (1) perceived organizational support has a significant effect on employee performance, (2) employee engagement has a significant effect on employee performance, (3) job satisfaction partially mediates the effect of perceived organizational support on employee performance, and (4) job satisfaction does not mediate the effect of Employee engagement on employee performance.
\end{abstract}

Keywords: perceived organizational support; employee engagement; satisfaction work; performance

\section{PENDAHULUAN}

Karyawan sebagai bagian vital dalam setiap organisasi perlu mendapat perhatian dari organisasi. Bentuk perhatian organisasi ini biasanya disebut dukungan organisasional persepsian (Perceived Organizational Support /POS) (Riggle et al., 2009). Dukungan organisasional persepsian didefinisikan sebagai keyakinan organisasi menghargai nilai-nilai dan kontribusi karyawan dan memperhatikan kesejahteraannya (Eisenberger et al., 1986). Teori pertukaran sosial dan teori dukungan sosial meyakini bahwa dukungan menjadi sebuah katalisator untuk meningkatkan hasil kerja karyawan yang positif. Perilaku ini dapat berupa tambahan hasil, peningkatan kualitas perilaku, dan kinerja (Rhoades and Eisenberger, 2002). Pertimbangan hubungan pertukaran antara organisasi dan karyawan akan menimbulkan hubungan resiprokal yang saling menguntungkan (Rhoades \&Eisenberger, 2002). Hubungan organisasi dengan 
karyawan didukung oleh teori dukungan organisasi (Eisenberger et al., 1986). Dalam hal ini ada keyakinan bahwa organisasi akan selalu membantu karyawannya ketika karyawannya menghadapi stress yang tinggi atau mengalami tuntutan pekerjaan yang harus diselesaikan dalam waktu singkat atau dalam menghadapi pekerjaan dengan tekanan waktu yang sangat cepat.

Keberhasilan suatu organisasi sangat dipengaruhi oleh kinerja individu karyawannya (Annisa dan Soeling, 2013). Salah satu faktor yang mempengaruhi kinerja karyawan adalah kinerja individual yang di dalamnya terdapat tingkat usaha yang dicurahkan seorang individu untuk memiliki rasa semangat bekerja dan keterikatan yang tinggi (Mathis dan Jackson, 2006). Employee engagement yang tinggi akan meningkatkan kineja individu (Robinson et al, 2008). Baumruk dan Gorman (2006) menyatakan bahwa jika karyawan memiliki rasa keterikatan yang ini terhadap perusahaan, hal tersebut dapat meningkatkan tiga perilaku dari karyawan, yakni: (1) karyawan lebih aktif dalam memberikan masukkan, (2) karyawan akan lebih loyal terhadap organisasi, dan (3) karyawan akan memberikan waktu, usaha dan inisiatif lebih untuk kesuksesan organisasi. Employee engagement atau seringkali diterjemahkan sebagai keterikatan karyawan, merupakan kontributor penting dalam upaya retensi SDM dalam organisasi. Menurut Hughes dan Rog (2008), employee engagement adalah hubungan emosional dan intelektual yang tinggi yang dimiliki oleh karyawan terhadap pekerjaannya, organisasi, pimpinan, atau rekan kerja yang memberikan pengaruh untuk menambah nilai tambah dalam pekerjaannya. Seseorang yang telah memutuskan untuk bekerja dalam suatu perusahaan, namun belum sepenuhnya menjalankan semua tugas-tugasnya maka ia dikatakan belum memiliki engagement atau keterikatan terhadap pekerjaan yang menjadi tanggung jawabnya.

Faktor lain yang dapat dimungkinkan menjadi prediktor kinerja adalah kepuasan kerja (Job Satisfaction) (Rosita dan Yuniati, 2016). Menurut Parsons (1998), kepuasan kerja berhubungan dengan karyawan yang mengembangkan diri dalam organisasi atas dasar pengalamannya. Kepuasan kerja berhubungan dengan organisasi, personal, dan faktor-faktor interpersonal (Kavanaugh et al., 2006). Faktor-faktor organisasional tersebut berpengaruh terhadap kepuasan kerja karyawan, termasuk di dalamnya adalah otonomi karyawan, stres emosional, dan sejumlah pekerjaan mingguan dalam sebulan (Ruggiero, 2005).

PT. Lafarge Holcim Tbk. Cilacap Plant yang mengalami perubahan nama menjadi PT. Solusi Bangun Indonesia Tbk sejak 11 Februari 2019, merupakan salah satu industri manufaktur yang cukup besar di Indonesia, bergerak dalam bidang pembuatan semen. Berdasarkan hasil 
wawancara peneliti dalam melakukan pra survey, ditemukan bahwa kinerja karyawan PT. Solusi Bangun Indonesia Tbk sedang mengalami penurunan. Selama kuartal I dan kuartal II/2020, kinerja perusahaan cukup terganggu akibat pandemi virus corona. Hal ini berimbas pada penurunan volume penjualan. Dampak pandemi Covid-19 lebih terasa pada kuartal II/2020. Adapun sepanjang kuartal I/2020, guncangan terhadap pasar disebabkan oleh curah hujan tinggi. Kondisi ini membuat banyak proyek pembangunan terhenti sehingga penjualan semen ikut turun secara signifikan. Total penjualan semen dan material lain mengalami penurunan yang cukup signifikan pada Mei 2020, meskipun kenaikan penjualan sudah mulai terlihat Juni 2020 lalu. Pada kuartal I/2020, SMCB membukukan laba sebesar Rp68,42 miliar yang ditopang oleh pertumbuhan pendapatan serta efisiensi beban di berbagai lini. Laba yang dihasilkan perseroan jauh lebih baik dibanding perolehan pada periode yang sama tahun lalu. Pada kuartal I/2019, perseroan justru membukukan rugi senilai Rp123,02 miliar (Bisnis.com, 2020).

Penurunan produksi dan penjualan yang dialami PT. SBI ternyata tidak diiringi dengan keterampilan teknis semua karyawan dalam melaksanakan bidang tugas yang dihadapi. Saat ini PT.SBI sedang mengedepankan digitialisasi dalam menjalankan operasional perusahaan. Sistem yang semakin maju dan semua serba online mulai dari training online, meeting online, laporan keuangan dan sebagainya menuntut setiap SDM memiliki keterampilan digital yang memadai. Dukungan organisasional dan dari organisasi sangat dibutuhkan setia karyawan untuk menghadapi situasi sulit ini. Di samping itu, keterlibatan karyawan terhadap organisasi menjadi hal penting untuk meningkatkan kinerja organisasi. Kepuasan kerja yang rendah akibat tingkat penjualan dan produksi yang mengalami penurunan signifikan, kemungkinan besar menjadi penyebab kinerja karyawan yang mengalami penurunan. Dari latar belakang tersebut maka penelitian ini penting dilakukan dengan tujuan untuk menganalisis pengaruh dukungan organisasional persepsian dan employee engagement terhadap kinerja dimediasi oleh kepuasan kerja pada PT. Solusi Bangun Indonesia.

\section{Dukungan Organisasional Persepsian (Perceived of Organizational Support) dan Kinerja}

Dukungan organisasional persepsian merupakan persepsi karyawan terhadap bagaimana organisasi menghargai kontribusi mereka dan peduli terhadap kesejahteraan mereka (Eisenberger, 1986). Menurut Robbins \& Coulter (2014), tingginya tingkat dukungan organisasional mengarah kepada tingginya kepuasan kerja dan menurunkan turnover. Prawirosentono (2008) menyatakan kinerja adalah hasil kerja yang dapat dicapai oleh seseorang atau kelompok orang dalam suatu 
organisasi sesuai dengan wewenang dan tanggung jawab masing-masing dalam rangkaupaya mencapai tujuanorganisasi bersangkutan secara legal tidak melanggar hukum dan sesuai dengan moral maupun etika. Zainur (2010) mendefinisikan Kinerja merupakan keseluruhan proses bekerja dariindividu yang hasilnya dapat digunakan landasan untuk menentukan apakah pekerjaan individu tersebut baik atau sebaliknya Kinerja juga merupakan keluaran yang dihasilkan oleh fungsi-fungsi atau indikator suatu pekerjaan atau profesidalam waktu tertentu (Wirawan, 2009).

Penelitian Zagenczyk et al. (2011); Siswanti et all (2018) mencatat adanya hubungan positif dan signifikan antara POS dengan variabel-variabel lainnya (seperti: keadilan organisasional, kepuasan kerja, employee engagement, dan kinerja). Ahmed et al. (2013), Bogler dan Nir (2012), Chung et al. (2012), serta Muse dan Wadsworth (2012) mencatat adanya hubungan yang kuat dan signifikan antara POS dengan variabel-variabel tersebut di atas, meskipun ada juga beberapa peneliti yang menghasilkan hubungan lemah atau sedang (Cheung, 2013; Karatepe, 2012b; Francis, 2012; Newman et al., 2012; Simosi, 2012; Sulea et al., 2012);sementara sebagian kecil hasil riset menunjukkan hubungan yang tidak signifikan ( Cho and Treadway, 2011; Elstad et al., 2013; Jakbsen dan Andersen, 2013; Landsman, 2008; Tuzun dan Kelmci, 2012; Wickramasinghe dan Perera, 2012).

\section{Dukungan Organisasional Persepsian (Perceived of Organizational Support) dan Kepuasan Kerja}

Robbins (2015) mendefinisikan kepuasan kerja sebagai mana seseorang memihak pada pekerjaannya, berpartisipasi aktif di dalamnya, dan menganggap produktivitasnya penting bagi harga diri. Menurut Kreitner and Kinicki (2000) kepuasan kerja sebagai perasan positif atau negatif dari pekerjaannya dan reaksi emosional yang ditunjukkan pada situasi yang berbeda sesuai dengan pekerjaannya. Riset Eisenberger et al. (1997); Miao et al. (2011); Islam et al. (2014) menunjukkan adanya pengaruh positif dan signifikan dukungan organisasional terhadap kepuasan kerja.Ketika dukungan dari organisasi cukup tinggi terhadap karyawan, maka tingkat kepuasan karyawan meningkat.

\section{Employee Engagement dan Kinerja}

Employee engagement adalah hubungan emosional dan intelektual yang tinggi yang dimiliki oleh karyawan terhadap pekerjaannya, organisasi, manajer, atau rekan kerja yang memberikan pengaruh untuk menambah usahanya sebagai upya mengoptimalkan pekerjaannya 
(Hughes dan Rog, 2008). Albrecht (2010) employee engagement adalah hasrat anggota organisasi terhadap pekerjaan mereka dimana mereka bekerja dan mengekspresikan diri mereka secara fisik, kognitif, dan emosi selama melakukan pekerjaan. Employee engagement merupakan tingkat komitmen dan keterlibatan seorang karyawan terhadap organisasi dan nilai-nilai organisasi (Anitha, 2014). Menurut Macey et al (2009) rasa engaged adalah suatu keterikatan, keterlibatan, komitmen, keinginan untuk berkontribusi, rasa memiliki (sense of belonging), loyalitas dan rasa bangga terhadap pekerjaan dan juga perusahaannya. Menurut Wrlbourne (2007), Engagement bukanlah sikap, melainkan merupakan sebuah perilaku yang menjadi pendorong kinerja sebuah organisasi. Apabila perusahaan memiliki karyawan yang rasa keterikatannya tinggi akan membuat karyawan betah untuk bekerja di tempat tersebut dan kepuasannya juga meningkat (Rahmawati, 2013). Hasil penelitian Anitha (2013); Ahmed \& Nawaz (2015); Dajani (2015) menunjukkan adanya pengaruh positif dan signifikan employee engagement terhadap kinerja. Siddhanta dan Roy (2010) menyatakan bahwa employee engagement dapat menciptakan kesuksesan bagi perusahaan salah satunya melalui peningkatan kinerja karyawan.

\section{Employee Engagement dan Kepuasan Kerja}

Riset Lianasari et al (2017); Kamalanabhan \& Mayuri (2009); Thakur (2014) menyatakan bahwa employee engagement berpengaruh positif signifikan terhadap kepuasan kerja karyawan. Ketika tingkat komitmen dan keterlibatan seorang karyawan terhadap organisasi dan nilai-nilai organisasi semakin tinggi maka berkontribusi dalam meningkatkan kepuasan kerjanya.

\section{Kepuasan Kerja dan Kinerja}

Penelitian Rosita \& Yuniati (2016); Crossman \& Abou (2003); Dugguh \& Dennis (2014); Khan et al. (2012; Inuwa (2016) menunjukkan kepuasan kerja memiliki pengaruh yang signifikan dan positif terhadap variabel kinerja karyawan. Kinerja karyawan semakin baik apabila kepuasan kerja yang dirasakan oleh karyawan semakin baik. Kinerja dan kepuasan kerja karyawan yang semakin tinggi, tercapai karena adanya

\section{Dukungan organisasional persepsian-kepuasan kerja-kinerja}

Dukungan organisasional yang tinggi dapat berdampak terhadap peningkatan kepuasan kerja karyawan Eisenberger et al. (1997); Miao et al. (2011); Islam et al. (2014). Kepuasan kerja karyawan yang tinggi dapat meningkatkan kinerja karyawan Rosita \& Yuniati (2016); Crossman \& Abou (2003); Dugguh \& Dennis (2014); Khan et al. (2012; Inuwa (2016). 


\section{Employee engagement-kepuasan kerja-kinerja}

Keterikatan karyawan yang tinggi pada organisasi berdampak terhadap meningkatnya kepuasn kerja (Lianasari et al., 2017; Kamalanabhan \& Mayuri, 2009; Thakur, 2014). Kepuasan kerja yang meningkat akan membuat hasil kerja karyawan yang semakin baik.

\section{Hipotesis}

$\mathrm{H}_{1}$ : Dukungan organisasional persepsian berpengaruh positif terhadap kinerja karyawan

$\mathrm{H}_{2}$ : Employee engagement berpengaruh positif terhadap kinerja karyawan

$\mathrm{H}_{3}$ : Dukungan organisasional persepsian berpengaruh positif terhadap kinerja karyawan dimediasi kepuasan kerja

$\mathrm{H}_{4}$ : Employee engagement berpengaruh positif terhadap kinerja karyawan dimediasi kepuasan kerja

\section{Model Penelitian}

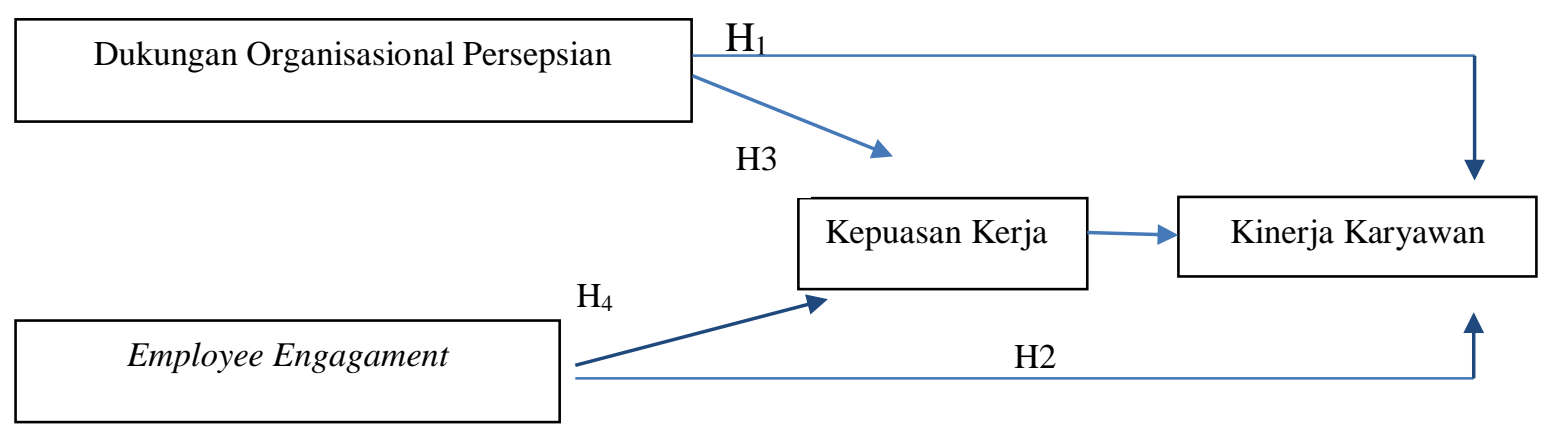

\section{Gambar 1. Model Penelitian}

\section{METODE PENELITIAN}

Metode penelitian ini menggunakan survey, yakni mengambil sejumlah sampel dari total populasi. Metode pengambilan sampel mengunakan rumus Slovin.

\section{Populasi dan Sampel}

Populasi penelitian ini adalah karyawan tetap di PT. Solusi Bangun Indonesia Tbk, khususnya pada pabrik di area Cilacap, jawa tengah sejumlah 339. Dengan rumus Slovin diperoleh sampel minimal sejumlah 185 karyawan. Pengambilan sampel dilakukan dengan metode acak sederhana. 


\section{Pengukuran}

Instrumen dalam penelitian ini mengadopsi dari peneliti sebelumnya. Dukungan organisasional pesepsian diukur dengan instrumen yang dikembangkan oleh Eissenberger et al (1986) sejumlah 8 item. Employee engagement diukur dengan instrumen yang dikembangkan oleh Schaufeli dan Bakker (2003), sejumlah 17 iem dengan 3 indikator, yakni: vigor, dedication dan absorpsion. Kepuasan kerja diukur dengan menggunakan Job Satisfacion Questionair Minnesota, sebanyak 20 item. Kinerja karyawan diukur denan insrumen yang dikembangkan oleh Prawirosentono (2008).

\section{Pengujian Instrumen}

Uji instrumen dilakukan dengan uji validitas menggunakan confirmatory factoranalysis dan uji reliabilitas. Hasil uji reliabilitas ditunjukkan oleh Cronbach Alpa. Batas uji reliabilitas menurut Hair et al. (2006) adalah $\alpha$ 0,7; sedangkan apabila $\alpha=0,6$, dapat diterima dalam penelitian eksploratori.

\section{Metode Pengujian Hipotesis}

$\mathrm{H}_{1}$ dan $\mathrm{H}_{2}$ diuji dengan regresi linier sederhana. $\mathrm{H}_{3}$ dan $\mathrm{H}_{4}$ diuji dengan path analysis, model Baron dan Kenny (1986). Uji ini dilakukan dengan empat (4) tahapan, yakni: menguji pengaruh langsung variabel independen terhadap dependen, menguji pengaruh langsung variabel independen terhadap variabel mediasi, menguji pengaruh variabel mediasi terhadap variabel dependen, dan menguji pengaruh independen variabel dan variabel mediasi terhadap variabel dependen.

\section{HASIL DAN PEMBAHASAN}

\section{Profil Responden}

Berdasarkan Tabel 1 menunjukkan bahwa mayoritas karyawan pada PT. Solusi Bangun Indonesia Tbk berusia antara 44 s/d 49 tahun. Mayoritas usia karyawan berumur lebih dari 30 tahun. Responden berjenis kelamin laki-laki yaitu sebanyak 175 orang dengan persentase 94.6\%, dan sisanya sejumlah 10 orang memiliki jenis kelamin perempuan dengan persentase sebesar 5.4\%. Mayoritas karyawan berpendidikan SMA yaitu sebanyak 115 orang dengan persentasi 62,1\%. Masa kerja paling lama selama $17 \mathrm{~s} / \mathrm{d} 22$ tahun. 
Tabel 1. Diskriptif Responden

\begin{tabular}{|c|c|c|c|c|}
\hline No. & Karakteristik & Kategori & Jumlah & Prosentase $(\%)$ \\
\hline \multirow[t]{6}{*}{1.} & Usia & $26 \mathrm{~s} / \mathrm{d} 31$ & 26 & $14.1 \%$ \\
\hline & & 32 s/d 37 & 13 & $7.0 \%$ \\
\hline & & $38 \mathrm{~s} / \mathrm{d} 43$ & 38 & $20.5 \%$ \\
\hline & & 44 s/d 49 & 80 & $43.2 \%$ \\
\hline & & $50 \mathrm{~s} / \mathrm{d} 56$ & 28 & $15.1 \%$ \\
\hline & & Total & 185 & \\
\hline \multirow[t]{3}{*}{2.} & Jenis Kelamin & Laki-Laki & 175 & $94.6 \%$ \\
\hline & & Perempuan & 10 & $5.4 \%$ \\
\hline & & Total & 185 & \\
\hline \multirow[t]{6}{*}{3.} & Pendidikan & SD & 5 & $2.7 \%$ \\
\hline & & SMP & 9 & $4.9 \%$ \\
\hline & & SMA & 115 & $62.1 \%$ \\
\hline & & Diploma & 21 & $11.4 \%$ \\
\hline & & Sarjana & 35 & $18.9 \%$ \\
\hline & & Total & 185 & \\
\hline \multirow[t]{6}{*}{4.} & Masa Kerja & $5 \mathrm{~s} / \mathrm{d} 10$ & 37 & $20.0 \%$ \\
\hline & & $11 \mathrm{~s} / \mathrm{d} 16$ & 5 & $2.7 \%$ \\
\hline & & 17 s/d 22 & 88 & $47.6 \%$ \\
\hline & & $23 \mathrm{~s} / \mathrm{d} 28$ & 50 & $27.0 \%$ \\
\hline & & $29 \mathrm{~s} / \mathrm{d} 35$ & 5 & $2.7 \%$ \\
\hline & & Total & 185 & \\
\hline
\end{tabular}

Sumber: hasil olah data primer, 2020

\section{Analisis Diskriptif Variabel}

Tabel 2. Diskriptif Variabel

\begin{tabular}{cccccc}
\hline & $\mathrm{N}$ & Minimum & Maximum & Mean & Std. Deviation \\
\hline Dukungan Organisasional & 187 & 3,63 & 5,00 & 4,4056 &, 30758 \\
Employee Engagement & 187 & 3,00 & 5,00 & 4,3441 &, 43579 \\
Kepuasan Kerja & 187 & 3,65 & 4,75 & 4,3307 &, 22749 \\
Kinerja & 187 & 3,25 & 5,00 & 4,3711 &, 37252 \\
\hline
\end{tabular}

Sumber:olah data primer, 2020 
Dari tabel 2 dapat diketahui bahwa rata-rata diskripti variabel adalah tinggi karena memiliki nilai rata-rata di atas 4,00. Secara umum dapat dikatakan bahwa karyawan PT. Bangun Indonesia Tbk memiliki persepsi tinggi mengenai dukungan organisasional yang mereka rasakan selama ini, employee engagement yang bagus, kepuasan kerja tinggi dan kinerja yang tinggi.

\section{Hasil Uji Hipotesis}

Tabel 3. Pengaruh dukungan Organisasional Persepsian terhadapKinerja

\begin{tabular}{ccccccc}
\multicolumn{8}{c}{ Unstandardized } & \multicolumn{2}{c}{ Standardized } \\
\multicolumn{1}{c}{ Coefficients } & Coefficients & \\
& Model & $B$ & Std. Error & Beta & t & Sig. \\
\hline 1 & (Constant) & 1,441 &, 329 & & 4,384 &, 000 \\
& Dukungan &, 665 &, 074 &, 549 & 8,939 &, 000 \\
\hline & Organisasional &, 65 & &
\end{tabular}

a. Dependent Variable: Kinerja

Sumber: olah data primer

Dari uji tahap 1 tersebut diperoleh hasil bahwa variabel employee engagement memiliki nilai signifikansi t sebesar $0,000<0,05$, maka dapat disimpulkan Ho ditolak. Artinya dukungan organisasional berpengaruh positif dan signifikan terhadap kinerja karyawan pada PT. Solusi Bangun Indonesia Tbk yang berarti tahap 1 signifikan (H1 terdukung)

Tabel 4. Pengaruh Employee Engagement terhadap Kinerja

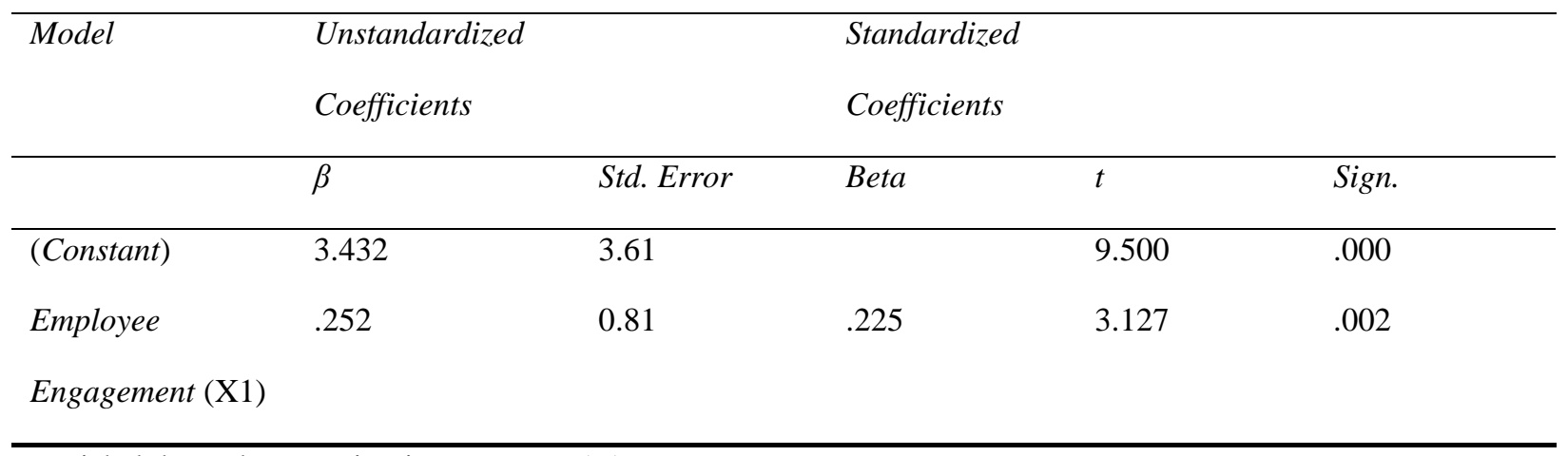

Variabel dependen : Kinerja Karyawan (Y)

Sumber: olah data primer

Dari hasil perhitungan (uji tahap 2) diperoleh hasil bahwa variabel employee engagement memiliki nilai signifikansi t sebesar 0,002 < 0,05, maka dapat disimpulkan Ho ditolak. Artinya 
employee engagement berpengaruh positif dan signifikan terhadap kinerja karyawan pada PT.

Solusi Bangun Indonesia Tbk, yang berarti $\mathbf{H 2}$ terdukung.

Tabel 5. Pengaruh Dukungan Organisasional Persepsian dan Employee Engagement terhadap Kepuasan Kerja

(Uji tahap 3)

\begin{tabular}{|c|c|c|c|c|c|c|}
\hline \multirow{2}{*}{\multicolumn{2}{|c|}{ Model }} & \multicolumn{5}{|c|}{$\begin{array}{l}\text { Standardized } \\
\text { Coefficients }\end{array}$} \\
\hline & & $B$ & Std. Error & Beta & $\mathrm{t}$ & Sig. \\
\hline \multirow[t]{3}{*}{1} & (Constant) & 3,727 & ,223 & & 16,712 &, 000 \\
\hline & Dukungan Organisasional & ,343 & ,062 & ,464 & 5,560 &, 000 \\
\hline & Employee Engagement & 209 & 044 &,- 400 & $-4,796$ &, 000 \\
\hline
\end{tabular}

a. Dependent Variable: Kepuasan Kerja

Dari tabel 5 diketahui ada pengaruh positif signifikan dukungan organisasional dan employee engagement terhadap kepuasan kerja.

\section{Tabel 6. Pengaruh Dukungan Organisasional dan Kepuasan Kerja terhadap Kinerja}

\begin{tabular}{|c|c|c|c|c|c|c|}
\hline \multirow[b]{2}{*}{ Model } & & \multicolumn{2}{|c|}{ Unstandardized Coefficients } & \multicolumn{2}{|l|}{$\begin{array}{l}\text { Standardized } \\
\text { Coefficients }\end{array}$} & \multirow[b]{2}{*}{ Sig. } \\
\hline & & $B$ & Std. Error & Beta & $\mathrm{t}$ & \\
\hline 1 & (Constant) & 3,085 & ,469 & & 6,575 &, 000 \\
\hline & Dukungan Organisasional & ,743 &, 072 & ,614 & 10,256 & ,000 \\
\hline & Kepuasan Kerja & ,459 & ,098 &,- 280 & $-4,686$ & ,000 \\
\hline
\end{tabular}

a. Dependent Variable: Kinerja

Dari tabel 6 diketahui bahwa ada pengaruh positif dan signifikan dukungan organisasional persepsian dan kepuasan kerja terhadap kinerja.

Tabel 7. Pengaruh Employee Engagement dan Kepuasan Kerja terhadap Kinerja

\begin{tabular}{|c|c|c|c|c|c|c|}
\hline \multirow[b]{2}{*}{ Model } & & \multicolumn{2}{|c|}{ Unstandardized Coefficients } & \multicolumn{2}{|l|}{$\begin{array}{l}\text { Standardized } \\
\text { Coefficients }\end{array}$} & \multirow[b]{2}{*}{ Sig. } \\
\hline & & $B$ & Std. Error & Beta & $\mathrm{t}$ & \\
\hline 1 & (Constant) & ,808 & 106 & & 7,645 & 000 \\
\hline & Employee Engagement &, 841 & 011 & ,984 & 78,475 &, 000 \\
\hline & Kepuasan Kerja &,- 021 & 021 &,- 013 & $-1,016$ & ,311 \\
\hline
\end{tabular}

a. Dependent Variable: Kinerja 
Dari tabel 7 diketahui bahwa ada pengaruh positif dan signifikan employee engagement dan kepuasan kerja terhadap kinerja.

Tabel 4.8. Pengaruh kepuasan Kerja terhadap Kinerja

\begin{tabular}{|c|c|c|c|c|c|c|}
\hline \multirow[b]{2}{*}{ Model } & & \multicolumn{2}{|c|}{ Unstandardized Coefficients } & \multicolumn{2}{|c|}{$\begin{array}{l}\text { Standardized } \\
\text { Coefficients }\end{array}$} & \multirow[b]{2}{*}{ Sig. } \\
\hline & & $\mathrm{B}$ & Std. Error & Beta & $\mathrm{t}$ & \\
\hline 1 & (Constant) & 5,359 &, 517 & & 10,366 &, 000 \\
\hline & Kepuasan Kerja &,- 228 &, 119 &,- 139 & $-1,914$ & 057 \\
\hline
\end{tabular}

a. Dependent Variable: Kinerja

Dari tabel-tabel tersebut di atas,dapat diketahui bahwa kepuasan kerja mampu memediasi pengaruh dukungan organisasional perwepsian terhadap kinerja karyawan pada PT. Solusi Bangun Indonesia Tbk, karena uji tahap 1 signifikan, uji tahap 2 (pengaruh dukungan organisasional terhadap kepuasan kerja signifikan), uji tahap 3 (pengaruh kepuasan kerja terhadap kinerja, signifikan), dan uji tahap 4 (pengaruh dukungan organisasional dan kepuasan kerja terhadap kinerja, signifikan). Dalam hal ini kepuasan kerja memediasi secara parsial. Dengan demikian hipotesis 3 terdukung.

Dari tabel di atas, diketahui bahwa kepuasan kerja tidak memediasi pengaruh employee engagement terhadap kinerja. Hal ini diketahui dari:

1. Uji tahap 1 :pengaruh employee engagement terhadapkinerja, signifikan

2. Uji tahap 2: pengaruh employee engagement terhadap kepuasan kerja, signifikan

3. Uji tahap 3: pengaruh kepuasan kerja terhadap kinerja, signifikan

4. Uji tahap 4: pengaruh employee engagement dan kepuasan terhadap kinerja, tidak signifikan

Dengan demikian hipotesis 4 yang menyatakan bahwa kepuasan kerja memediasi pengaruh employee engagement terhadap kinerja karyawan PT. Solusi Bangun Indonesia Tbk, tidak terdukung.

\section{HASIL DAN PEMBAHASAN}

Hasil penelitian menunjukkan bahwa terdapat pengaruh positif dukungan orgnisasional persepsian terhadap kinerja karyawan PT. Solusi Bangun Indonesia Tbk. Hal ini berarti dukungan organisasional yang diberikan kepada karyawan selama ini cukup bagus dan memenuhi harapan karyawan.Dukungan organisasional dapat diberikan dalam bentuk: motivasi kepada karyawan untuk meningkatkan karier, pemberian sebagian wewenang dari atasan, kesempatan melanjutkan 
studi, kesempatan mengikuti pelatihan sesuai kebutuhan karyawan, kesempatan berkomunikasi secara intensif dengan atasan dan rekan kerja tanpa adanya tekanan. Hasil ini sesuai dengan riset Kambu et al., 2012; Metria \& Riana, 2018; Wisaksono, 2018; Putra et al., 2016).

Hasil penelitian menunjukkan bahwa terdapat pengaruh yang positif dan signifikan employee engagement terhadap kinerja karyawan pada PT. Solusi Bangun Indonesia Tbk. Hal ini berarti bahwa employee engagement memiliki pengaruh yang besar terhadap kinerja karyawan karena apabila karyawan memiliki employee engagement yang tinggi maka dapat dipastikan kinerja karyawan meningkat. Karyawan yang memiliki keterlibatan yang tinggi dengan perusahaan dan pekerjannya, ditandai dengan rasa antusias dan bangga dalam bekerja serta sulit untuk melepaskan diri dari pekerjaannya maka secara langsung akan menghasilkan kinerja yang maksimal. Dengan kata lain, karyawan yang memiliki ikatan kuat dengan perusahaan maka akan meningkatkan performansi dalam pekerjaannya. Terbukti dengan tingkat employee engagement karyawan PT. Solusi Bangun Indonesia Tbk termasuk dalam kategori sangat tinggi dengan persentase sebesar $84,9 \%$ diikuti dengan tingkat kinerja karyawan yang juga termasuk dalam kategori sangat tinggi dengan persentase sebesar $89,7 \%$.

Selain itu, PT. Solusi Bangun Indonesia Tbk memiliki karyawan dengan usia lebih dari 30 tahun, yang artinya pada usia tersebut seseorang memasuki tahap pemantapan dan pemeliharaan dimana karyawan sudah memiliki pengalaman, keterampilan serta pengetahuan yang cukup dalm memberikan kinerjanya yang terbaik untuk kemajuan perusahaan. PT. Solusi Bangun Indonesia Tbk memiliki karyawan dengan usia yang cukup matang yang diharapkan memiliki tingkat employee engagement yang tinggi dan kinerja yang maksimal terhadap perusahaan. PT. Solusi Bangun Indonesia Tbk merupakan industri manufaktur dengan karakteristik pekerjaan yang dilakukan lebih bersifat teknik dimana kemampuan ini lebih dimiliki oleh laki-laki sehingga karyawan laki-laki di perusahaan ini lebih banyak dibandingkan dengan karyawan perempuan. Penelitian yang dilakukan oleh Schaufeli et al (2006) menemukan bahwa karyawan laki-laki lebih engaged dalam bekerja dibandingkan karyawan perempuan, terutamapada jenis pekerjaan yang membutuhkan kemampuan fisik ekstra dan pekerjaan dominan dilakukan di lapangan. Adanya pengaruh employee engagement tehadap kinerja, membuat perusahaan dapat meningkatkan kinerja karyawan melalui upaya peningkatan employee engagement. Hasil penelitian ini didukung oleh penelitian sebelumnya yang dilakukan oleh Lianasari et al (2017); 
Anitha J. (2013) dan Dajani (2015) menyatakan bahwa Employee Engagament berpengaruh secara positif dan signifikan terhadap Kinerja Karyawan.

Hasil penelitian menunjukkan bahwa kepuasan kerja memediasi pengaruh dukungan organisasional persepsian terhadap kinerja karyawan PT. Solusi Bangun Indonesia Tbk. Hal ini berarti, ketika dukungan organisasional cukup tinggi dari perusahaan maka berpengaruh terhadap peningkatkan kepuasan kerja karyawan (Han et al., 2012). Kepuasan kerja karyawan yang meningkat akan meningkatkan kinerja karyawan (Engko et al., 2008; Nur, 2013; Rosita \& Yuniati, 2016). Kepuasan kerja dalam riset ini berperan sebagai pemediasi parsial, karena ada pengaruh langsung dukungan organisasional terhadap kinerja karyawan.

Hasil penelitian ini menunjukan bahwa tidak ada pengaruh positif dan signifikan employee engagement terhadap kinerja karyawan dengan kepuasan kerja sebagai variabel intervening, yang artinya kepuasan kerja tidak mampu menjadi variabel intervening (pemediasi) employee engagement terhadap kinerja karyawan. Peningkatan employee engagement ternyata tidak meningkatkan kepuasan kerja kayawan di perusahaan ini, meskipun ada pengaruh positif kepuasan kerja terhadap kinerja karyawan. Ketika seorang karyawan memiliki engagement yang tinggi terhadap perusahaan, maka rasa kepuasan yang dimiliki karyawan terhadap pelayanan yang diberikan oleh perusahaan terhadap setiap pekerjaan yang mereka lakukan belum tentu meningkat sehingga belum tentu berdampak positif terhadap kinerja. Hasil penelitian ini tidak mendukung penelitian Lianasari et al (2017); Wibawa dan Soedarsono (2016). Menurut analisis peneliti, dari wawancara dengan beberapa responden ditemukan fakta bahwa keterlibatan karyawan yang meningkat pada karyawan PT. SBI Tbk di pabrik Cilacap, Jawa tengah disebabkan keinginan mereka untuk tetap dipertahankan oleh perusahaan, mengingat pada kondisi pandemi akibat covid19 menyebabkan semakin sulit memperoleh pekerjaan baru apabila dikeluarkan dari perusahaan. Hal ini terutama dialami oleh SDM yang telah berusia di atas 40 tahun, tingkat pendidikan SMA atau di bawahnya, jaringan bisnis masih sedikit, serta keterampilan yang terbatas. Employee engagement yang meningkat dapat berpengaruh langsung terhadap variabel lain selain kepuasan kerja. Hal ini ditunjukkan oleh penelitian Luthan dan Peterson (2002) bahwa employee engagement berpengaruh signifikan terhadap self efficacy; komitmen dan usia karyawan (Kordbacheh, 2014); stres kerja (Anthony et al., 2017). Penelitian Harter et al. (2002); Likewise et al. (2004); dan Juhdi et al.(2013) menunjukkan employee engagement berpengaruh negatif signifikan terhadap turnover intention. 
Dari hasil riset ini diketahui bahwa kepuasan kerja memediasi pengaruh employee engagement terhadap kinerja, karena employee engagement dapat berpengaruh langsung. Menurut analisis peneliti, hal ini bisa saja terjadi pada objek, bahwa ada kemungkinan variabel mediasi lain yang dapat mempengaruhi meningkatnya kinerja. Variabel-variabel tersebut seperti kepemimpinan, budaya organisasi, komitmen organisasional. Peningkatan kinerja dapat dilakukan oleh organisasi melalui beragam cara.

\section{KESIMPULAN DAN SARAN}

Hasil riset menunjukkan: dukungan organisasional persepsian berpengaruh signifikan terhadap kinerja karyawan, employee engagement berpengaruh signifikan terhadap kinerja karyawan, kepuasan kerja memediasi parsial pengaruh dukungan organisasional persepsian terhadap kinerja karyawan, kepuasan kerja tidak memediasi pengaruh employee engagement terhadap kinerja karyawan. Penelitian ini memiliki keterbatasan, seperti: pengambilan sampel mengambil satu objek perusahaan, dan jumlah populasinya pun terbatas. Penelitian lanjutan sebaiknya mengembangkan objeknya pada perusahaaan manufaktur lain, perusahaan jasa, maupun organisasi nir laba, organisasi pendidikan, instansi pemerintah dan sebagainya dengan menambah jumlah populasi. Pengambilan data dalam riset ini dilakukan dengan coss sectional (satu waktu), penelitian lanjutan dapat mencoba melakukan metode time series, meskipun tantangannya lebih tinggi. Metode ini bermanfaat untuk melihat konsistensi responden dalam menjawab kuesioner. Penelitian lanjutan dapat mencoba mencoba variabel lain yang berpotensi sebagai variabel mediasi atau moderasi, seperti : stres kerja, komitmen organisasional, self efficacy, turnover intention.

Penelitian ini memberi kontribusi praktis yakni menjadi acuan pimpinan organisasi untuk mempertahankan employee engagement yang dimiliki karyawan agar tetap tinggi, dengan beragam cara seperti: meningkatkan fasilitas kerja, memberi kesempatan karyawan untuk mengikuti pelatihan SDM sesuai kebutuhan pasar, meningkatkan kompensasi bagi karyawan yang mampu mencapai kinerja melebihi target, memberi kesempatan karyawan berprestasi untuk studi lanjut dengan beasiswa dari organisasi, mengembangkan sistem karier yang jelas bagi karyawan. Ketika employee engagement meningkat diharapkan kinerja 


\section{REFERENSI}

Ahmed, I., Ismail, W.K.W., Amin, S.M. and Nawaz, M.M. (2013), "Social exchange perspective of individual guaxi network: evidence from Malaysian Chinese employees", Chinese Management Studies, Vol. 7 No. 1, pp. 127-140.

Albrecht, S. L. (2010). Handbook of employee engagement perspective, issues, research, and practice. USA: Edward Elgar publishing limited.

Anitha J. (2014). Determinants of Emploee Engagement and Their Impact on Employee Performance. International Journal of Productivity and Performance Management. Vol. 63, No. 3.

Annisa, Auzi dan Pantius Drahen Soeling. (2013). Pengaruh Employee Engagement terhadap Kinerja Karyawan PT. Chandra Sakti Utama Leasing Jakarta. Jurnal FISIP-UI.

Anthony-McMann, P. E., Ellinger, A. D., Astakhova, M., \& Halbesleben, J. R. (2017). Exploring different operationalizations of employee engagement and their relationships with workplace stress and burnout. Human Resource Development Quarterly, 28(2), 163-195.

Baron, Reuben. M., \& Kenny, David. A. (1986). The Moderator-Mediator Variable Distinction in Social Psychological Research: Conceptual, Strategic, and Statistical Considerations. Journal of Personality and Social Psychology, Vol. 1, No. 6: 1173-1182.

Baumruk, R., B. Gorman. (2006). Why Managers are Crucial to Increasing Engagement. Strategic HR Review, pp. 24-27

Bogler, R. and Nir, A.E. (2012), “Theimportanceofteachers'perceivedorganizationalsupportto job satisfaction, what empowerment got to do with it?", Journal of Educational Administration, Vol. 50 No. 3, pp. 287-306.

Cheung, M.F.Y. (2013), "The mediating role of perceived organizational support in the effects of interpersonal and informational justice on organizational citizenship behavior", Leadershipand Organization Development Journal, Vol. 34 No. 6, pp. 551-572.

Cho, J. and Treadway, D.C. (2011), "Organizational identification and perceived organizational support as mediator of the procedural justice-citizenship behavior relationship: a crosscultural constructive replication", European Journal of Work and Organizational Psychology, Vol. 20 No. 5, pp. 631-653.

Chung, T.-L., Rutherford, B. and Park, J. (2012), "Understanding multifaceted job satisfaction of retail employees", International Journal of Retail and Distribution Management, Vol. 40 No. 9, pp. 699-716.

Crossman, A., \& Abou-Zaki, B. (2003). Job satisfaction and employee performance of Lebanese banking staff. Journal of Managerial Psychology.

Dajani, Maha Ahmed Zaki. (2015). The Impact of Employee Engagement on Job Performance and Organisational Commitment in the Egyptian Banking Sector. Journal of Business and Management Sciences. Vol.3, No.5.

Davis, Keith., \& Newstrom, John. (1985). Organizational behavior: readings and exercises. McGraw-Hill.

Dewi, C. N. C., Bagia, I. W., \& Susila, G. P. A. J. (2018). Pengaruh stres kerja dan kepuasan kerja terhadap kinerja karyawan pada bagian tenaga penjualan UD Surya Raditya Negara. Bisma: Jurnal Manajemen, 4(2), 154-161.

Dugguh, S. I., \& Dennis, A. (2014). Job satisfaction theories: Traceability to employee performance in organizations. Journal of business and management, 16(5), 11-18. 
Eisenberger, R., Cummings, J., Armeli, S., \& Lynch, P. (1997). Perceived organizational support, discretionary treatment, and job satisfaction. Journal of applied psychology, 82(5), 812.

Eisenberger, R., Huntington. R, Hutchison, S., dan Sowa. D. (1986). Perceived Organizations Support. Journal of Applied Psychology. Vol. 73 No.3.

Elstad, E., Christophersen, K.-A. and Turmo, A. (2013), "Antecedents of organizational citizenship behavior among educators in language education for adult immigrants in Norway", Adult Education Quarterly, Vol. 63 No. 1, pp. 78-96.

Engko, C. (2008). Pengaruh kepuasan kerja terhadap kinerja individual dengan self esteem dan self efficacy sebagai variabel intervening. Jurnal bisnis dan akuntansi, 10(1), 1-12.

Francis, C.A. (2012), “The mediating force of 'face': supervisor character and statuss related to perceived organizational support at work outcomes", Journal of Leadership and Organizational Studies, Vol. 19 No. 1, pp. 58-67.

Han, S. T., Nugroho, A., Kartika, E. W., \& Kaihatu, T. S. (2012). Komitmen afektif dalam organisasi, perceived organizational support, dan kepuasan kerja. Jurnal manajemen dan kewirausahaan, 14(2), 109-117.

Harter, J. K., Schmidt, F. L., \& Hayes, T. L. (2002). Business-unit level relationship between employee satisfaction, employee engagement, and business outcomes: A meta-analysis. Journal of Applied Psychology, 87(2), 268-279. http://dx.doi.org/10.1037/00219010.87.2.26

Hughes, Julia Christensen dan Evelina Rog. (2008). Talent Management, A Strategy for Improving Employee Recruitment, Retention, and Engegement within Hospitality Organization. International Journal of Contemporary Hospitality Management, Vol. 20, No.7, pp.743-757.

Inuwa, M. (2016). Job satisfaction and employee performance: An empirical approach. The Millennium University Journal, 1(1), 90-103.

Ishfaq Ahmed, Muhammad Musarrat Nawaz, (2015) "Antecedents and outcomes of perceived organizational support: a literature survey approach", Journal of Management Development, Vol. 34 Issue: 7, pp.867-880

Islam, T., Ahmad, U. N. U., \& Ahmed, I. (2014). Exploring the relationship between POS, OLC, job satisfaction and OCB. Procedia-Social and Behavioral Sciences, 114, 164-169.

Jakbsen, M. and Andersen, S.C. (2013), "Intensifying social exchange relationships in public organizations: evidence from a randomized field experiment", Journal of Policy Analysis and Management, Vol. 32 No. 1, pp. 60-82.

Juhdi, N., Pa'wan, F., \& Hansaram, R. M. K. (2013). HR Practices and Turnover intention: The mediating roles of organizational commitment and organizational engagement in a selected region in Malaysia. The International Journal of Human Resource Management, 24(15), 3002-3019. http://dx.doi.org/10.1080/09 585192.2013.763841

Kamalanabhan, T. J., Sai, L. P., \& Mayuri, D. (2009). Employee engagement and job satisfaction in the information technology industry. Psychological reports, 105(3), 759-770.

Kambu, A. (2012). Pengaruh Leader-Member Exchange, Persepsi Dukungan Organisasional, Budaya Etnis Papua dan Organizational Citizenship Behavior, terhadap Kinerja Pegawai pada Sekda Provinsi Papua. Jurnal Aplikasi Manajemen, 10(2), 262-272.

Karatepe, O.M. (2012a), "Perceived organizational support, career satisfaction, and performance outcomes: a study of hotel employees in Cameroon”, International Journal of Contemporary Hospitality Management, Vol. 24 No. 5, pp. 735-752. 
Karatepe, O.M. (2012b), "The effects of coworker and perceived organizational support on hotel employee outcomes: the mediating role of job embeddedness", Journal of Hospitality and Tourism Research, Vol. 36 No. 4, pp. 495-516.

Kavanaugh, J., Duffy, J., \& Lilly, J. (2006). The relationship between job satisfaction and demographic variables for healthcare professionals. Management Research News, 29(6), 304-325.

Khan, A. H., Nawaz, M. M., Aleem, M., \& Hamed, W. (2012). Impact of job satisfaction on employee performance: An empirical study of autonomous Medical Institutions of Pakistan. African journal of business management, 6(7), 2697-2705.

Kordbacheh, N., Shultz, K. S., \& Olson, D. A. (2014). Engaging mid and late career employees: The relationship between age and employee engagement, intrinsic motivation, and meaningfulness. Journal of Organizational Psychology, 14(1), 11-24.

Kreitner, R. \&Kinicki A. (2000). Organizational Behavior 5th edition, Boston: Mc Graw-Hill.

Kuncoro, Mudrajad. (2003). Metode Riset Untuk Bisnis \& Ekonomi. Jakarta: Erlangga.

Mahardika, Lorenzo.A. (2020). "Solusi Bangun Indonesia (SMCB) Kaji Ulang Rencana Belanja Modal”, Dalam Bisnis.com. 9 Juli 2020. Jakarta.

Landsman, M.J. (2008), "Pathways to organizational commitment", Administration in Social Work, Vol. 32 No. 2, pp. 105-132.

Lianasari, Paulus Wardoyo, dan Djoko Santoso. (2017). Pengaruh Stres Kerja, Employee Engagement, dan Kedisiplinan terhadap Kinerja dengan Kepuasan Kerja sebagai Variabel Intervening pada Karyawan CV. Karya Manunggal Semarang. Neo-Bis. Volume 11, No.2.

Luthans, F., \& Peterson, S. J. (2002). Employee engagement and manager self-efficacy. The Journal of Management Development, 21(5), 376-387.

Macey, W.H., B. Schneider., K.M Barbera., S.A Young. (2009). Employee Engagement: Tools for Analysis, Practice, and Competitive Advantage. United States: Wiley-Blackwell.

Mathis dan Jackson. (2009). Manajemen Sumber Daya Manusia, Edisi 10. Jakarta : Salembada Empat.

Metria, K., \& Riana, I. G. (2018). Pengaruh Dukungan Organisasi Terhadap Komitmen Organisasional Dan Kinerja Pegawai. E-Jurnal Ekonomi dan Bisnis Universitas Udayana, 7(9), 2117-2146.

Miao, R. T. (2011). Perceived organizational support, job satisfaction, task performance and organizational citizenship behavior in China. Journal of Behavioral and Applied Management, 12(2), 105.

Muse, L.A. and Wadsworth, L.L. (2012), “An examination of traditional versus non-traditional benefits", Journal of Managerial Psychology, Vol. 27 No. 2, pp. 112-131.

Newman, A., Thanacoody, R., \& Hui, W. (2012). The effects of perceived organizational support, perceived supervisor support and intra-organizational network resources on turnover intentions. Personnel Review.

Nur, S. (2013). Konflik, stres kerja dan kepuasan kerja pengaruhnya terhadap kinerja pegawai pada Universitas Khairun Ternate. Jurnal EMBA: Jurnal Riset Ekonomi, Manajemen, Bisnis dan Akuntansi, 1(3).

Parson, Marsha. B. (1998). A Review of Procedural Acceptability in Organizational Behavior Management. Journal of Organizational Behavior, Vol. 18, Issue 23: 173-190.

Prawirosentono, Suryadi. (2008). Kebijakan Kinerja Karyawan. Yogyakarta: BPFE.Sugiyono. 2011. Metode Penelitian Kuantitatif, Kualitatif dan R \& D. Bandung: Afabeta. 
Putra, I. D. P. G. W., Sintaasih, D. K., \& Putra, M. S. (2016). Pengaruh dukungan organisasional terhadap kepuasan kerja dan komitmen organisasional. E-Jurnal Ekonomi dan Bisnis Universitas Udayana, 5, 3531-3560.

Rachmawati, M. (2013). Employee Engagement Sebagai Kunci Meningkatkan Kinerja Karyawan. Among Makarti, Vol.6 No.12.

Reneé Roberts-Turner, Pamela S. Hinds, John Nelson, Juanda Pryor, Nellie C. Robinson, and Jichuan Wang. (2014), Effects of Leadership Characteristics on Pediatric Registered Nurses' Job Satisfaction. PEDIATRIC NURSING/September-October, Vol. 40/No. 5

Rhoades, L. and Eisenberger, R. (2002), "Perceived organizational support: a review of the literature", Journal of Applied Psychology, Vol. 87 No. 4, pp. 698-714.

Riggle, R.J., Edmondson, D.R. and Hansen, J.D. (2009), "A meta-analysis of the relationship between perceived organizational support and job outcomes: 20 years of research. Journal of business research, Vol. 62 No. 10, pp. 1027-1030.

Robbins, P. Stephen., \& Judge, Timothy. A. (2015). Organizational Behavior, 16th Edition. Pearson.

Robbins P. Stephen, Mary Coulter. (2014). Management. TwelfthEdition.United States: Pearson Education Limited.

Rosita, Titik dan Tri Yuniati. (2016). Pengaruh Kepuasan Kerja terhadap Kinerja Karyawan dengan Komitmen Organisasional sebagai Variabe Intervening. Jurnal Ilmu dan Riset Manajemen. Volume 5, No.1.

Ruggiero, J.S. (2005). Health, work variables, and job satisfaction among nurses. Journal of Nursing Administration, 33(5), 254-263.

Siddhanta, Abhijit dan Roy, Debalina. (2010). Employee engagement - Engaging the 21st century workforce. Asian Journal of Management Research.

Simosi, M. (2012), "Disentangling organizational support construct: the role of different sources of support to newcomers' training transfer and organizational commitment", Personnel Review, Vol. 41 No. 3, pp. 301-320.

Siswanti, Yuni., Kurnianto, H.K., Hartono. A., Prajoho, W., \& Palupi, M. (2018). Constructing Model Preposition of Employee Justice Climate, Perceived Organisational Support, Employee Engagement, and Counterproductive Work Behavior. The 31 Th Proceeding of Ibima.Millan, Italy, 25-26 April.

Sulea, C., Virga, D., Maricutoiu, L.P., Schaufeli, W., Dumitru, C.Z. and Sava, F.A. (2012), "Work engagement as mediator between job characteristics and positive and negative extra-role behaviors", Career Development International, Vol. 17 No. 3, pp. 188-207.

Thakur, P. (2014). A research paper on the effect of employee engagement on job satisfaction in IT sector. Journal of Business Management \& Social Sciences Research, 3(5), 31-39.

Tuzun, I.K. \& Kelmci, R.A. (2012), "Organizational and supervisory support in relation to employee turn over intentions”, Journal of Managerial Psychology, Vol.27 No.5, pp.518534.

Wickramasinghe, V. and Perera, S. (2012), "Effects of perceived organization support, employee engagement, and organizational citizenship behavior on quality performance", Total Quality Management and Business Excellence, available at: http://dx.doi.org/10.1080/ 14783363.2012.728855.

Wirawan. (2009). Evaluasi Kinerja Sumber Daya Manusia. Jakarta: Salemba Empat.

Wisaksono, A. (2014). Analisis Keterlibatan Kerja dan Dukungan Organisasi terhadap Kinerja dengan Mediasi Komitmen Organisasional. Fokus Ekonomi: Jurnal Ilmiah Ekonomi, 9(1). 
Yousef, D.A. (2000), Organizational Commitment: A Mediator of the Relationships of Leadership Behavior with Job Satisfaction and Performance in a Non-Western Country. Journal of Managerial Psychology, 15, 6-24.

Zagenczyk, T.J., Givney, R., Few, W.T. and Scott, K.L. (2011), "Psychological contract and organizational identification: the mediating effect of perceived organizational support", Journal of Labor Research, Vol. 32, pp. 254-281.

Zainur, Roziqin Muhammad (2010). Kepuasan Kerja. Malang: Averroes Press. 